\title{
Positron emission tomography/magnetic resonance imaging (PET/MRI): An update and initial experience at HC-FMUSP
}

\author{
Marcelo A. Queiroz ${ }^{1,2 *} @$, Felipe de Galiza Barbosa ${ }^{2}$, Carlos Alberto Buchilguel ${ }^{1,2}$, Giovanni Guido Cerri ${ }^{1,2}$ \\ ${ }^{1}$ Institute of Radiology (InRad), Hospital das Clínicas da Faculdade de Medicina da USP (HC-FMUSP), São Paulo, SP, Brazil \\ ${ }^{2}$ Service of Medical Imaging, Hospital Sírio-Libanês, São Paulo, SP, Brazil
}

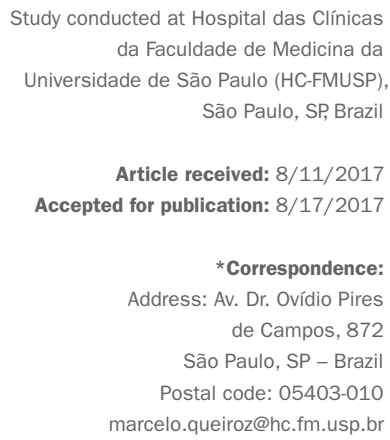

\section{SUMMARY}

The new technology of PET/MRI is a prototype of hybrid imaging, allowing for the combination of molecular data from PET scanning and morphofunctional information derived from MRI scanning. Recent advances regarding the technical aspects of this device, especially after the development of MRI-compatible silicon photomultipliers of PET, permitted an increase in the diagnostic performance of PET/MRI translated into dose reduction and higher imaging quality. Among several clinical applications, PET/MRI gains ground initially in oncology, where MRI per se plays an essential role in the assessment of primary tumors (which is limited in the case of PET/CT), including prostate, rectal and gynecological tumors. On the other hand, the evaluation of the lungs remains an enigma although new MRI sequences are being designed to overcome this. More clinical indications of PET/MRI are seen in the fields of neurology, cardiology and inflammatory processes, and the use of PET/MRI also opens perspectives for pediatric populations as it involves very low radiation exposure. Our review aimed to highlight the current indications of PET/MRI and discuss the challenges and perspectives of PET/MRI at HC-FMUSP.

Keywords: Positron-Emission Tomography. Tomography, X-Ray Computed. Magnetic Resonance Spectroscopy. Diagnostic Imaging. Review.

\section{INTRODUCTION}

Positron emission tomography/magnetic resonance imaging (PET/MRI) stands out as the most advanced method in the field of imaging diagnosis, in addition to being one of the precursors of a new modality in the field, namely molecular imaging. Combining the molecular information made available by PET with the morphological and functional data from MRI allows for a complete and detailed assessment of the patient.

The idea underlying the development of hybrid technologies, i.e. technologies combining different diagnostic methods, was first established in 1991 in Geneva when Townsend et al. developed a PET unit with gaps between its detectors, which permitted the integration of another imaging method: as per the suggestion of Swiss cancer surgeon Rudi Egeli, computed tomography (CT) was chosen. The PET/CT concept was thus born. Nevertheless, it only became a prototype for clinical use in 1998 in Pittsburgh, offering sequential PET and CT acquisitions with a diagnostic quality. About 300 patients underwent $\mathrm{PET} / \mathrm{CT}$ scans, with the promising results having encouraged the development of a PET/CT unit for commercial use. Then, in 2001, the first PET/CT unit was made available by three different manufacturers. Its success was instantaneous and significant for clinical routine, to the extent that in 2006 exclusive PET units were no longer marketed, and in 2008 more than 2,500 PET/CT units were already available worldwide. ${ }^{1}$

At the same time, the idea of integrating MRI into PET was also proposed. However, the technical difficulty involved is much greater, given the incompatibility of PET detectors with magnetic fields. Also in 1997, the possibility of simultaneous phantom PET and MRI acquisitions was demonstrated. ${ }^{2}$ Only in 2006, in Germany, after the development of software that can be used to fuse PET and MRI images, the first PET/MRI prototype was developed for exclusive evaluation of the brain. ${ }^{3}$ The PET/MRI concept for use in humans has been proven, albeit with 
many technical limitations for its incorporation into clinical practice. In 2010, the first PET/MRI unit became commercially available. But as it involved the integration of PET/CT and MRI units in the same room (Philips Healthcare) or in different rooms (GE healthcare), it was thus referred to as sequential technology. In 2011, the first PET/MRI with integrated technology for simultaneous acquisitions (Siemens Healthcare) was launched for clinical use. ${ }^{4}$ More recently, in 2014 , a more modern model, also relying on an integrated, time-of-flight technology, was made available.

Shortly after its arrival in Brazil, PET/MRI was initially used for scientific purposes, especially as a research tool, and has been showing promising results in several fields, mainly oncology, neurology and cardiology. Currently included in the clinical routine at some centers and referred for some indications, PET/MRI faces encouraging prospect as the future of imaging diagnosis, for it allows a noninvasive, functional assessment coupled to a high morphological resolution.

\section{TECHNICAL ASPECTS}

\section{General technical concepts}

The combination of PET and MRI in a single unit that permits simultaneous acquisitions, although intuitively simple, is technically much more complex than it appears to be. What made this integration impossible for many years was the incompatibility between MRI's strong magnetic field and PET's photomultiplier tubes. The initial solutions for this problem proposed that sequential acquisitions should be made. One of such solutions was the PET/CT and MRI trimodality system (General Electrics - GE), where the patient undergoes sequential MRI and $\mathrm{PET} / \mathrm{CT}$ scans (following no previously defined order) in separate rooms. This system uses a stretcher with a floating device for patient transferring that prevents him or her from moving about, which therefore allows for the subsequent and accurate fusion of images. ${ }^{5}$ After that, a sequential PET/MRI system was launched, but it comprised a single unit (Ingenuity - Philips) where PET detectors are separated from the magnet, linked by a connecting table that transports the patient in order to acquire the images from each component separately. ${ }^{6}$ Although more realistic, this latter solution remains sequential in nature and loses a sense of simultaneity as far as acquisition is concerned.

It was necessary to create a PET detector with MRIcompatible semiconductors in order to make a true architectural fusion possible. The first solution for this great challenge came about via avalanche photodiode detectors (APD), which resist magnetic fields up to 9.4 Tesla. It was with this technology that the first commercial simultaneous PET/MRI unit (Biograph - Siemens) was launched. ${ }^{7}$ Subsequently, a new technology of magneticfield-compatible PET detectors was developed, i.e. detectors with silicon photomultipliers (SiPM). ${ }^{8}$ Such technology was implemented in the market as the second simultaneous PET/MRI machine (Signa - GE) to be made available. The detectors with SiPM displayed greater detection sensitivity, hence promising clinical gains such as dose reduction with better image quality and thus allowing greater flexibility of PET/MRI protocols. ${ }^{9-11}$ These are the two PET/MRI machines available on the market offering simultaneous acquisition. They are equipped with 3-Tesla magnetic field MR, with one of them relying on time-of-flight (TOF) technology.

Following the great challenge of integrating the PET detector crystals into a $3 \mathrm{~T}$ magnetic field, the next challenge was a need for a very accurate correction of the detected gamma rays due to the attenuation correction (AC) caused by different types of tissues.

MR-based attenuation correction (MRAC) is broadly based on a tissue classification using the T1-weighted MRI sequence (T1w) Dixon, ${ }^{11-13}$ differently from the tissue density on which PET/CT AC is based (CTAC). The postprocessed Dixon generates four distinct sequences, "Water only" (or "Water"), "Fat only" (or "Fat"), "In-phase" (or "IP"); and "Out-of-phase" (or "OP”). In combining such tissue information, an algorithm in the unit makes a tissue classification, namely air, lung, fat and soft tissue. MRAC is generated by means of this tissue stratification. This technique was already validated by some studies for clinical use in the two modalities of simultaneous PET/ MRI units, either with or without time-of-flight (TOF) technology. ${ }^{14-17}$ Another method used for generating the MRI in the skull portion involves an atlas. This technique is based on MRI recognition of anatomical patterns, generating what would be a pseudo-CT scan of the skull and an attenuation correction map. ${ }^{18}$

One problem that both current MRAC techniques generate is that they do not correctly factor the "bone" for that AC, which causes PET/MRI to still attract ongoing criticism regarding standard uptake value (SUV) quantification of bone lesions. To this end, recent MR-sequence studies with the use of zero echo time (ZET) showed that this technique can overcome the current technical limitation, thereby generating a more accurate and reliable quantitative MRAC. ${ }^{19,20}$ 


\section{Technical concepts of image acquisition}

PET/MRI acquisition is said to be truly simultaneous when PET data are acquired while MRI sequences are being performed in the same region. As is the case with other sectional methods, it all begins with the acquisition of MRI localizer images (the equivalent to a CT scout scan in PET/CT), which aims at defining the imaging coverage area and serves as a basis for programming both the PET and MRI acquisition sequences. The region of the body to be scanned is divided into smaller portions called "beds" according to the size of the PET detector ring. The axial length of the bed in the latest generation PET/MRI scanner is $25 \mathrm{~cm}$, with an axial bed position overlap of $23 \%$. Depending on the patient's body length in a full-body study (head to thigh), usually 5-7 beds are acquired. PET imaging is acquired in sequential blocks of bed positions, from cranial to caudal, and it is necessary to define beforehand how many beds are to be acquired and the amount of time acquiring data at each single bed position. The acquisition time of each bed is similar to that in PET/CT, between 2-4 minutes, as recommended by international guidelines, but modifiable in accordance with the desired protocol. The MRI sequences are then programmed for each bed in accordance with the protocol established for the context. Therefore, if longer MRI sequences within a particular segment of the body are required, it is important to program this in advance in order for PET time to be proportional.

When PET acquisition is initiated, a sequence for optimizing magnetic field homogeneity is quickly acquired for each bed. The T1 Dixon referring to MRAC is sequentially acquired. Altogether, the whole process takes less than 30 seconds. Thereafter, the remaining anatomical and functional sequences follow in accordance with the stipulated protocol.

Once the simultaneous acquisition is completed, it is possible to program new segmental acquisitions of some region of interest, either simultaneous PET/MRI or MRI - only scans, for instance, post-contrast sequences, without necessarily involving PET acquisition. When everything is finalized, then it is possible to proceed with post-processing and generating the fusion of PET data, MRAC data and other desired sequences, which are then sent for analysis.

\section{Cinical applications}

\section{Oncology}

Head and neck neoplasms

MRI plays an already well-established role in local staging of head and neck neoplasms, especially in preoperatively assessing the tumor's relationship with adjacent structures, detecting infiltration of the prevertebral fascia or perineural dissemination. Furthermore, MRI is superior to $\mathrm{CT}$ in detecting occult primary neoplastic sites in patients with cervical lymph node metastases. With regard to imaging quality, besides MRI's well-known superiority in spatial resolution, it is associated with lower prevalence of artifacts stemming from metal dental artifacts, which usually hampers assessment when using $\mathrm{CT}^{21}{ }^{21}$ The same applies to comparing PET/MRI versus PET/CT, favoring the greater sensitivity of the former in $\mathrm{T}$ staging, detecting occult primary neoplastic sites, and evaluating tumors of the oropharynx and oral cavity.

In relation to $\mathrm{N}$ and $\mathrm{M}$ staging, there is an important limitation of the imaging methods with respect to diagnostic accuracy. CT and MRI basically take into account morphological alterations or, occasionally, biological changes, such as increased vascularization and hypercellularity detected by the functional sequences of diffusion and perfusion MRI, respectively. ${ }^{22,23}$ PET imaging, despite the spatial limitation of PET methods that does not allow the diagnosis of metastases of less than $5 \mathrm{~mm}$, contributes with an evaluation at the molecular level, either relative to glycolytic metabolism, with the widely available FDG (fluorodeoxyglucose), or hypoxia, with the less known 18F-FMISO and 18F-FAZA. Therefore, the synergism of hybrid imaging methods, especially PET/MRI, can minimize such limitation by combining morphological, biological/functional and molecular information. ${ }^{24,25}$ In the evaluation of metastatic disease, PET/CT does have a relative advantage, given the higher prevalence of mediastinal lung and lymph node metastases, well-demonstrated by PET/CT, as compared to PET/MRI, which still needs to overcome some limitations regarding pulmonary parenchymal evaluation. The importance of whole-body evaluation is also due to the high prevalence (approximately $15 \%$ ) of synchronous neoplasms, mainly in the esophagus and lung. ${ }^{21}$

In the evaluation of response to therapy, PET/MRI also displays diagnostic accuracy similar to that of PET/CT, with the additional ability to specify additional findings possibly related to the disease. In a post-treatment context, changes induced by the treatment, mainly surgery and radiotherapy, lead to the distortion of the anatomy, which hinders the differentiation between residual and relapsed disease. There is no consensus regarding the ideal timing for conducting a PET scan following the end of treatment. Nevertheless, an interval of at least 8 weeks is recommended in an attempt to minimize post-therapy inflammatory changes, hence avoiding false positives. For followup, as recurrence usually occurs within two years after 
treatment, at least another two additional annual hybrid PET studies (at 12 and 24 months) are recommended.

$\mathrm{PET} / \mathrm{MRI}$ can also potentially assist in the planning of radiotherapy. The development of new units compatible with PET and MRI drives the use of PET/MRI for delineating the primary tumor with more consistent data than employing MRI alone. ${ }^{26,27}$

As far as quantification by PET/MRI is concerned, SUVmax measurements are comparable to those achieved by PET/CT and applicable to studies in humans. ${ }^{28,29} \mathrm{Semi-}$ quantitative data, such as standard uptake value (SUV), total lesion glycolysis (TLG) and tumor metabolic volume (TMV), made available by PET, can be used as prognostic predictors, identifying patients at greatest risk of therapeutic failure who could benefit from a more aggressive therapeutic approach and server as markers of survival. ${ }^{30-32}$

Thus, PET/MRI could potentially replace PET/CT in the evaluation of head and neck tumors, providing the data required for staging, evaluating treatment response, planning radiotherapy, and predicting the prognosis in one single examination.

\section{Thoracic neoplasms}

Among the thoracic neoplasms with potential clinical application, the ones that stand out the most are lung cancer, mesothelioma, and breast cancer.

\section{Lung cancer}

PET/CT constitutes the reference imaging method for the staging of non-small cell lung cancer, offering high diagnostic accuracy for the detection and delineation of primary tumors; CT scans are acquired during deep inspiration. Furthermore, the ability to detect regional lymph node disease and distant metastases gives PET/CT gold standard status in evaluating lung neoplasms. ${ }^{33}$

Recent studies indicate similar diagnostic accuracy of PET/MRI in evaluating lung cancer, despite its low ability to detect lung nodules by using conventional sequences, especially if those are smaller than $1.0 \mathrm{~cm} .{ }^{34}$ Still, its multiparametric PET/MRI evaluation capability allows this occasional limitation to be overcome. One of its potentials relates to the use of $\mathrm{T} 2$-weighted high-resolution sequences, which aid in characterizing thoracic wall invasion. In addition, the integration of diffusion, ultra-short echo-time sequences allows for a better evaluation of the pulmonary parenchym. ${ }^{35-37}$ For the assessment of $\mathrm{N}$ and $\mathrm{M}$ staging, PET imaging has a high negative predictive value, even though the positive predictive value is low. ${ }^{38}$ The incorporation of new sequences and radiopharmaceuticals, such as FLT, a marker of cell proliferation, can be determinant when assessing lung neoplasms, especially so with regard to evaluating treatment response and prognostic prediction. ${ }^{39,40}$

\section{Breast cancer}

The most prevalent malignant neoplasm in women is also associated with a high mortality rate. Usually, breast cancer staging is performed with MRI for local evaluation and, in more advanced cases, with PET/CT for detection of lymph node disease and, mainly, distant metastases. FDG PET/MRI may offer benefits for both local and systemic staging. ${ }^{41}$ The first advantage is a lower radiation exposure (about $50 \%$ of the PET/CT dose). The second one refers to the detection rate of metastatic lesions, i.e. PET/MRI's greater sensitivity when associated with FDG makes it more suitable for hepatic, cerebral and bone evaluation, but still limited for the identification of lung lesions. ${ }^{42,43}$

A recent study evaluated the clinical usefulness of FDG PET/MRI in breast cancer staging as compared to either PET or MRI alone. MRI showed greater detectability of metastatic lesions, and PET/MRI was responsible for changing the course of medical action in one third of the 36 patients who were analyzed. ${ }^{44}$ Another study demonstrated PET/MRI and MRI to have similar performances, with high specificity when characterizing regional lymph node disease. ${ }^{45}$ In addition, the possibility of using semiquantitative PET and MRI parameters can help characterize the expression of tumor biological factors, with a good correlation with intratumoral heterogeneity, Ki-67, triple-negative breast cancer and lymphovascular invasion. ${ }^{46}$

Given the importance of breast cancer on a molecular level, advancements in the development of new radiopharmaceuticals can be potentially useful in evaluating breast cancer. This applies to PET/CT with $\left[{ }^{18} \mathrm{~F}\right] \mathrm{NaF}$ (Fluoride) which, in combination with FDG PET/CT, showed diagnostic accuracy superior to that of whole-body MRI and bone scintigraphy with MDP. ${ }^{47}$ Another radiopharmaceutical having potential applications in breast cancer is $\left[{ }^{18} \mathrm{~F}\right]$ Fluoroestradiol (FES), an estrogen analog with a high correlation with tumor expression of estrogen in both primary tumors and metastases. ${ }^{48}$ FES PET shows very promising results, with a significant clinical impact (responsible for changes in the medical course of action in $48 \%$ of patients with a clinical dilemma $)^{49}$, and high conspicuity in detecting heterogeneity in estrogen receptor expression. It can potentially have a role as a predictor of treatment response, since lesions that uptake this radiopharmaceutical tend to respond to anti-hormonal therapy. ${ }^{49-51}$ 


\section{Abdominal neoplasms}

The liver is one of the organs most commonly affected by neoplasms, both primary (hepatocarcinoma and cholangiocarcinoma) and secondary (metastases, mainly colorectal carcinoma). For this reason, hepatic evaluation emerges as one of the main PET/MRI niches, capable of coupling the evaluation with functional sequences (diffusion and perfusion) and the use of a hepatobiliary contrast agent with the molecular information derived from PET. In doing so, it boosts diagnostic capacity. Furthermore, the evaluation of pancreatic neoplasms, including adenocarcinoma and neuroendocrine tumors, and pelvic neoplasms, such as adenocarcinoma of the prostate and gynecological malignancies, faces interesting prospects with PET/MRI.

\section{Liver}

The evaluation of the liver comprises one of the promising clinical applications of PET/MRI, given the high prevalence of hepatic metastases. Among the reasons for that are the excellent diagnostic performance of MRI when using functional sequences (diffusion and perfusion) and hepatobiliary contrast, and the superb detection ability of FDG PET to provide molecular information.

Some studies compared PET/MRI and PET/CT suitability for hepatic evaluation, with interesting results. Reiner et al. ${ }^{52}$ demonstrated that PET/MRI, with T1weighted and $\mathrm{T} 2$-weighted sequences alone and without the injection of a paramagnetic contrast agent, showed a diagnostic accuracy similar to that of contrast PET/CT relative to lesion detection. More recently, Lee et al. ${ }^{53}$ demonstrated that PET/MRI with a hepatospecific contrast media had a diagnostic performance that was significantly superior to those of CT and PET. This also indicates the possibility of using PET parameters as prognostic predictors of lower survival in the subgroup of high-uptake patients following neoadjuvant chemotherapy. PET/MRI with other radiopharmaceuticals, such as $\left[{ }^{68} \mathrm{Ga}\right.$ ]DOTA-TOC, is also highly suitable for diagnosing hepatic lesions, especially when combined with a hepatobiliary contrast agent. This makes for the combination of MRI detection with PET molecular information, i.e. somatostatin receptor expression in this specific case, thereby allowing the identification of patients who could benefit from peptide therapy. ${ }^{54}$

There is, therefore, an excellent niche for PET/MRI in liver evaluation, especially for evaluating liver metastases, with an excellent performance relative to detection, characterization and prognostic prediction.

\section{Pancreas}

Recently, the use of PET/CT for staging pancreatic adenocarcinoma was shown to be an excellent complementary method to the already well-established contrast CT. The results were obtained in a prospective, multicenter study conducted in England that evaluated the use of PET/CT in the diagnosis, staging and management of patients with suspected pancreatic cancer; staging required correcting in $14 \%$ of the cases. Comparatively, $45 \%$ of the 550 patients assessed with contrast CT, in turn, involved changes in the medical course of action. Furthermore, it was proven to be cost-effective, being especially useful in preventing unnecessary surgery in $20 \%$ of the patients. ${ }^{55}$

Few studies assessed the clinical use of PET/MRI in pancreatic evaluation. Chen et al. ${ }^{56}$ correlated clinical stage and prognoses for pancreatic and periampullary tumors with imaging biomarkers, diffusion by using MR spectroscopy, and glycolytic metabolism by using PET. They concluded that PET/MRI imaging biomarkers can predict clinical stage and progression-free survival in this group of patients.

\section{Neuroendocrine tumors (NETs)}

Gastroenteropancreatic NETs constitute the most common presentation of this tumor type and are often associated with lymph node and liver metastases. Most NETs have low FDG avidity and a high expression of somatostatin receptors, which depends directly on the cell proliferation index (the higher the Ki-67 and, consequently, the lower the tumor differentiation, the higher the FDG uptake and the lower the expression of somatostatin receptors). ${ }^{54}$ The use of PET radiopharmaceuticals analogous to somatostatin and the different types of $\left[{ }^{68} \mathrm{Ga}\right]$ DOTA have a promising role in evaluating NETs: they can be used in PET/MRI scans and their detectability is similar to $\mathrm{PET} / \mathrm{CT} .{ }^{57} \mathrm{~A}$ recent study compared PET/MRI with both DWI and MRI using a hepatospecific contrast agent. Both methods were shown to be highly accurate, with DWI having some limitations when differentiating malignant from benign lesions. ${ }^{58}$ Hence, the combination of MRI functional sequences, especially diffusion ones, with the PET information regarding receptor expression may represent the best imaging method in evaluating NETs.

\section{Prostate}

MRI represents the best method for diagnosing and staging prostate cancer. This, not only due to a better soft tissue contrast, but mainly because of the functional sequence values, such as diffusion and perfusion. ${ }^{59}$ 
The images obtained from FDG PET have low sensitivity for prostate cancer, since uptake is minimal in early and well-differentiated tumors and urinary excretion causes artifacts that undermine an appropriate analysis. Therefore, FDG PET/CT is a limited method for the evaluation of patients with prostate cancer. Other radiopharmaceuticals such as ${ }^{68} \mathrm{Ga}$-PSMA, ${ }^{18} \mathrm{~F}$-Choline and ${ }^{11} \mathrm{C}$-Choline are best suited for staging and evaluating the biochemical recurrence of prostatic adenocarcinoma. ${ }^{60}$

PET/MRI with diffusion is considered a promising tool in the pre-therapeutic evaluation of prostate tumors, allowing for the acquisition of detailed anatomic data in conjunction with molecular parameters. Choline, either ${ }^{18} \mathrm{~F}$ - or ${ }^{11} \mathrm{C}$-marked, is the most studied tracer to date. However, ${ }^{68} \mathrm{Ga}$-PSMA has been gaining strength due to its high diagnostic specificity. Choline PET/MRI can perform staging more effectively than MRI alone does - in terms of both primary tumor characterization and how it relates to adjacent structures, especially the prostatic capsule, and the possibility of guiding biopsy to an area of greater suspicion in clinically significant neoplasms. This reduces sampling errors of occasional random biopsies and positively influences therapeutic management. ${ }^{61,62}$ Yet, caution should be taken with false positives related to the use of choline, such as increased uptake in cases of benign prostatic hyperplasia and other findings not related to the disease, such as inflammatory mediastinal lymph nodes. ${ }^{63}$

In the context of tumor recurrence, usually detected as biochemical recurrence due to increased serum levels of prostate specific antigen (PSA), the evaluation using conventional imaging methods has low sensitivity for detecting disease outbreaks. ${ }^{68} \mathrm{Ga}$-PSMA stands out precisely as the best option for overcoming such limitations and identifying biochemically recurrent prostate cancer metastases. PET/MRI with ${ }^{68} \mathrm{Ga}$-PSMA may be the only imaging modality for conducting this evaluation, thereby reducing the number of false positives. ${ }^{64-66}$

Thus, it is believed that PET/MRI with non-FDG radiopharmaceuticals, especially ${ }^{68} \mathrm{Ga}$-PSMA, will represent the modality of choice for evaluating prostate cancer, both for staging it and carrying out a post-treatment evaluation, probably dispensing with any other methods.

\section{Uterus and ovaries}

MRI plays a major role in the local staging of gynecological malignancies, especially those of the uterine cervix, endometrium and ovaries. On the other hand, FDG PET/CT has greater accuracy in evaluating regional and distant staging, since it adds molecular parameters to essentially morphological alterations. ${ }^{67,68}$ Hence, PET/MRI might be considered a superior method for detecting, staging and restaging gynecologic malignancies, whose results are similar to those obtained from multiple examinations, all added up. ${ }^{69}$

T2-weighted sequences appropriately evaluate myometrial invasion in patients with endometrial cancer, cervical neoplasm infiltration of parametria and the lateral pelvic wall, and improved detection of ovarian and uterine lesions. ${ }^{69-71}$ Detectability of lymph node disease is enhanced, which allows the selection of patients needing lymphadenectomy, as is accuracy in identifying distant metastases, notably peritoneum, liver and bone metastases. ${ }^{72,73}$

\section{Lymphomas}

FDG PET/CT can be considered one of the pillars in the staging and evaluation of treatment response in high-grade lymphomas, known as Hodgkin's disease and diffuse large B-cell non-Hodgkin's lymphoma. The globally accepted guidelines for the assessment of lymphoproliferative disease recommend the use of PET/CT for the staging, posttreatment control and restaging of the disease, which, in these cases, leads to high exposure to ionizing radiation. ${ }^{74}$

Hence, PET/MRI constitutes an immediate advantage for the evaluation of this group of patients, represented by young patients with a high chance of cure. This method involves less exposure to radiation, which therefore minimizes its cumulative effects. ${ }^{75}$

Some studies with essentially preliminary data suggest PET/MRI could possibly replace PET/CT, while keeping similar diagnostic accuracy and good image quality. ${ }^{76,77}$ Diffusion has been widely investigated as an alternative to PET imaging in the evaluation of patients with lymphoma. However, DWI's high sensitivity alone is not enough to match the excellent accuracy of FDG PET. Still, it may enhance diagnostic performance when added to the PET/MRI protocol. ${ }^{78,79}$

\section{Neurology}

Cerebral evaluation is the most promising field for PET/MRI. Scholars say that the brain, from a functional standpoint, never remains the same along different moments in time. Thus, simultaneous PET and MRI acquisition permits the multiparametric evaluation (structural, functional, molecular) of different neurological pathologies, such as neurodegenerative dementias and disorders, epilepsy, neoplasms and psychiatric conditions. ${ }^{80}$

In addition to providing high-resolution morphological data, several other MRI properties allow for the evaluation of different brain processes: vascular anatomy (angioresonance), tissue kinetics (diffusion), cerebral 
perfusion patterns (perfusion), tissue metabolite concentration (spectroscopy), regional cerebral functional activation (functional MRI), brain fiber tract analysis (diffusion tensor imaging - DTI), oxygen consumption patterns (BOLD sequence), among others. ${ }^{81}$

PET also encompasses a wide range of molecular processes that can be evaluated: brain flow $\left(\mathrm{H}_{2}{ }^{15} \mathrm{O}\right)$, metabolism (FDG), blood volume $\left(\mathrm{C}^{15} \mathrm{O}\right)$, oxygen consumption $\left({ }^{15} \mathrm{O}\right)$, vascular permeability (labeled amino acids), nucleic acid synthesis (FLT), neurotransmitter evaluation (DOPA), receptor evaluation (raclopride), angiogenesis $\left({ }^{18} \mathrm{~F}-\mathrm{RGB}\right)$ are just a few examples. ${ }^{82}$

This means that there can be a real-time image of a multitude of complementary information. Nevertheless, it is essential to define what is really necessary and what could be just redundant. New techniques may demonstrate a local functional change in degenerative or autoimmune diseases even before the onset of clinical manifestations. It is also possible to better understand the mechanism of brain structures playing an important role in behavior and cognition, as well as other interesting questions that, until then, could only be evaluated in vitro or with histological studies. ${ }^{83}$

\section{Cardiovascular}

Hybrid PET/MRI raised new prospects for cardiovascular applications. PET/CT offered advances in the combined anatomical and functional evaluation of coronary heart disease and alterations in cardiac function, whereas MRI, in the other hand, with its high-definition and dynamic images, provides complementary information, such as those on myocardial blood flow, influencing. ${ }^{84}$

MRI offers a number of advantages over conventional methods such as CT and/or SPECT, some of which stand out: good soft-tissue contrast coupled with a high spatial resolution, myocardial perfusion evaluation, cardiac volume and ventricular function calculation, identification of valvular morphology and the ability to differentiate scars from viable myocardial tissue after infarction. PET, in turn, is the reference examination for detecting hemodynamically significant stenosis. Additionally, it can also be used to evaluate myocardial blood flow in rest and stress, and also to estimate coronary flow reserve.

Thus, the complementarity of PET/MRI information seems to be very promising for cardiovascular evaluation. More importantly, such information is readily applicable to the detection and characterization of coronary artery disease, evaluation of cardiomyopathies of different etiologies (ischemic, inflammatory/infiltrative) and study of myocardial viability. Furthermore, PET/MRI could be used to evaluate inflammatory response following myocardial infarction, atherosclerosis, thus identifying vulnerable plaques. It could even be used in stem cell therapy and characterization of neoangiogenesis. ${ }^{85}$

New non-FDG radiopharmaceuticals could assist in adding to the complementarity of PET information, such as the myocardial perfusion tracers currently being investigated, namely ${ }^{13} \mathrm{~N}$-ammonia, ${ }^{15} \mathrm{O}$-water, ${ }^{82} \mathrm{Rb}$ and ${ }^{18} \mathrm{~F}$-flurpiridaz. ${ }^{84,85}$

Thus, fusion of the most advanced methods for cardiac evaluation, i.e. PET and MRI, offers the best of the two modalities in one same procedure. Despite the need to establish its cost-effectiveness, PET/MRI could be the only method for cardiac evaluation allowing for a more complete evaluation of the main cardiac diseases and a significant impact on the therapeutic course of action.

\section{Inflammation/Infection}

PET/MRI offers the opportunity to evaluate several inflammatory processes, whose pathophysiology involves infiltration of immune-mediated cells, increased blood flow and capillary permeability, and transudation of proteins to the region involved.

In addition to its excellent soft-tissue contrast, MRI strengthens the analysis with the availability of sequences such as diffusion, which indirectly measures increases in tissue cellularity. FDG PET, on the other hand, permits the evaluation of processes with increased glucose consumption in cell recruitment of inflammatory processes. ${ }^{86}$

In diseases of the musculoskeletal system, FDG PET is highly sensitive in detecting joint changes, related both to overload (degeneration) and synovial inflammation. With MRI, the morphological analysis of structures such as bone marrow, muscles, tendons, ligaments, cartilage, joint capsule and fat becomes extremely viable. Thus, FDG PET/MRI permits the detection and characterization of diseases such as osteomyelitis, diabetic foot and rheumatoid arthritis. ${ }^{87,88}$

In the evaluation of inflammatory bowel disease, PET/MRI showed promising results when differentiating inflammatory from fibrotic stenoses in patients with Crohn's disease. In addition to the simultaneous acquisition of PET/MRI (not feasible in the sequential acquisition of PET/CT, which impairs the evaluation of intestinal loops with constant peristalsis), information such as location of different lesions in the gastrointestinal tract, detection of extra-luminal disease, and differentiation of fibrotic changes and inflammatory activity are essential for the proper clinical management of patients. ${ }^{89}$

More recently, data from a preclinical study showed the possibility of using PET/MRI with a specific radio- 
pharmaceutical, ${ }^{64} \mathrm{Cu}$-NODAGA, as a non-invasive, rapid, sensitive and specific method for detecting Yersinia enterocolitica infection. This approach was referred to as immunoPET and raised the prospect of using the method to detect different pathogens. ${ }^{90}$

\section{Pediatrics}

One of PET/MRI's immediate advantages is the lower exposure to ionizing radiation, with data ranging from 50 to $75 \%$ reduction relative to $\mathrm{PET} / \mathrm{CT}$. This becomes even more relevant when multiple scans are requested, as is the case with tumors submitted to different therapies. This aspect alone would have a high enough impact so as to guarantee the use of PET/MRI as a method of choice in the pediatric population. ${ }^{91-93}$

As an additional advantage, PET/MRI also allows for multiparametric characterization of some pathologies, thereby allowing a decline in the number of tests that need to be performed.

Among the most promising fields, PET/MRI can be used in children, oncology and neurology do stand out as the main ones. The evaluation of lymphomas, primary bone tumors, sarcomas, neuroblastomas and NETs are some of the potential clinical indications. While, in neurology, the detection of epileptogenic focus and brain tumors stand out as major points of interest. In addition to those, several other diseases may benefit from the use of PET/MRI, such as inflammatory rheumatic processes. ${ }^{91,92}$

\section{THE HC-FMUSP EXPERIENCE}

The HC-FMUSP (Hospital das Clínicas, Faculty of Medicine, University of São Paulo) was the first public hospital in Brazil to use the most advanced hybrid imaging technology as it purchased a PET/MRI unit which was made available both as a research tool and for clinical use at its Nuclear Medicine Service at the Radiology Institute.

The unit is a Signa PET/MRI, a state-of-the-art GE Healthcare system (Waukesha, USA), which integrates a 3.0T MRI with a PET that fully relies on high-resolution, high-sensitivity simultaneous time-of-flight technology (its sensitivity is about three times that of PET/CT).

Having started to operate on 26 April, 2016, the PET/MRI unit at HC-FMUSP has already performed a total of 30 scans for different indications, especially those in oncology (83.3\%), neurology (6.7\%) and inflammatory process $(6.7 \%)$ using two radiopharmaceuticals, ${ }^{18} \mathrm{~F}-\mathrm{FDG}$ $(80 \%)$ and ${ }^{68} \mathrm{Ga}$-DOTATOC (20\%). Of the 30 patients, 18 were female $(60 \%)$, with a mean age of 48.6 years ( $13-76$ years).

The scan protocol included the T1 LAVA, DWI and T2 SSFSE sequences and, in selected cases, T2 PROPELLER,
T2 STIR and T2 CUBE, with a mean duration of $50.3 \mathrm{~min}-$ utes (as compared to a mean of 25.1 minutes for PET/CT).

A comparison was drawn between PET/MRI and the $\mathrm{PET} / \mathrm{CT}$, both of which were performed sequentially, relative to semiquantitative data (SUVmax from PET/MRI vs. PET/CT SUVmax). The clinical impact of PET/MRI was categorized as: 0 , with no information added to PET/CT; 1 , addition of information without clinical/oncological relevance; and 2, addition of information with oncological/ therapeutic relevance.

With respect to semiquantitative data, SUVmax in PET/CT scans was 7.4 (ranging from 2.2 to 18.7) and PET/MRI scans was 10.9 (ranging from of 2.1 to 77.8 ). For malignant lesions, the mean late SUVmax (obtained from PET/MRI) was $82 \%$ higher than the early one (measured from PET/CT); whereas, for benign lesions, the mean late SUVmax was 19\% lower. PET/MRI exhibited a clinical impact having potential therapeutic relevance in $10 \%$ of the cases and added information without potential therapeutic relevance in $53.3 \%$ of the studies.

A selection with the main clinical cases studied with PET/MRI is illustrated in Figures 1 to 5, specifying the respective clinical impact as compared to PET/CT.

The installation of the PET/MRI unit raised new prospects in the field of advanced research, both basic and clinical research, with the development of at least six research projects already approved by the Research Ethics Committee. They involve external funding and some of them are already underway. They encompass the most different fields, some of which stand out, namely: a) oncology: neoplasms of the rectum, breast, prostate; b) neurology: traumatic brain injury, dementia, multiple sclerosis; and c) inflammation: inflammatory bowel disease. Furthermore, different radiopharmaceuticals are being used and produced in the radiopharmaceutical division at HC-FMUSP in an attempt to foster the development of research, such as ${ }^{18} \mathrm{~F}-\mathrm{FDG}$ (a marker of glycolytic metabolism), ${ }^{18} \mathrm{~F}-\mathrm{NaF}$ (a marker of osteoblastic activity), ${ }^{18} \mathrm{~F}$-FES (an estrogen analog), ${ }^{68} \mathrm{Ga}$-PSMA (a specific antigen from the prostatic membrane), ${ }^{68} \mathrm{Ga}-$ -DOTATATE (a somatostatin analogue), ${ }^{11} \mathrm{C}-\mathrm{PK} 11195$ (a neuroinflammation marker) and ${ }^{11} \mathrm{C}$-PIB (a marker of beta-amyloid plaques, used in the investigation of Alzheimer's disease).

Hence, it can be noticed that the PET/MRI unit at HC-FMUSP faces the prospect of a promising future in the institution. It will be used both in research purposes, which involve a range of prospective projects and development of different radiopharmaceuticals, and in translation into clinical routine. 


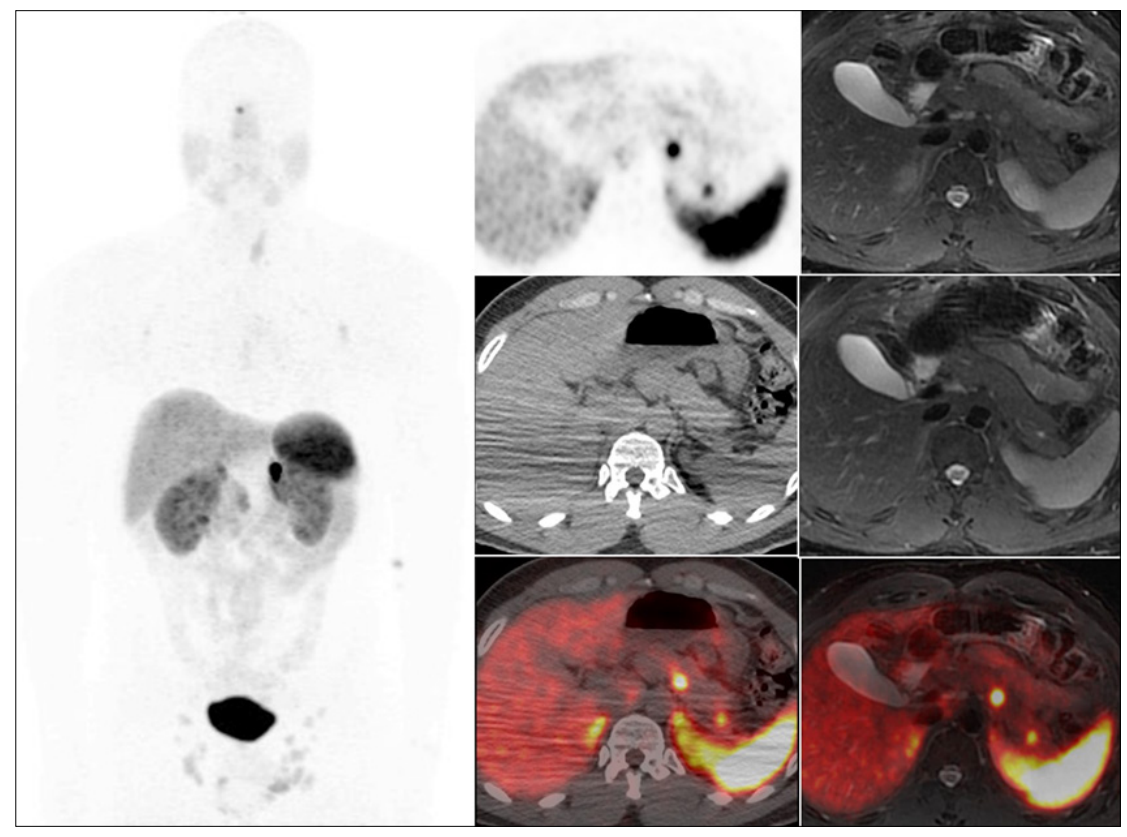

FIGURE 1 Coronal MIP PET and axial slices ofT2-weighted PET/CT and PET/MRI sequences. A 35-year-old male patient with a family history of NEM1 syndrome underwent abdominal CT scan, which revealed a para-aortic nodule. He also underwent a MIBG scintigraphy yielding a negative result. A ${ }^{68} \mathrm{Ga}$-DOTA PET scan was requested for investigation of neuroendocrine tumor. The patient had a history of thyroidectomy and pituitary hyperplasia. ${ }^{68} \mathrm{Ga}$-DOTATATO PET/CT and PET/MR images revealed: focal areas in the body and tail of the pancreas, uncorrelated to $\mathrm{CT}$ images and characterized as nodules on MRI with high T2 signal and diffusion restriction. This case demonstrates the superiority compared to MRI soft tissue contrast.

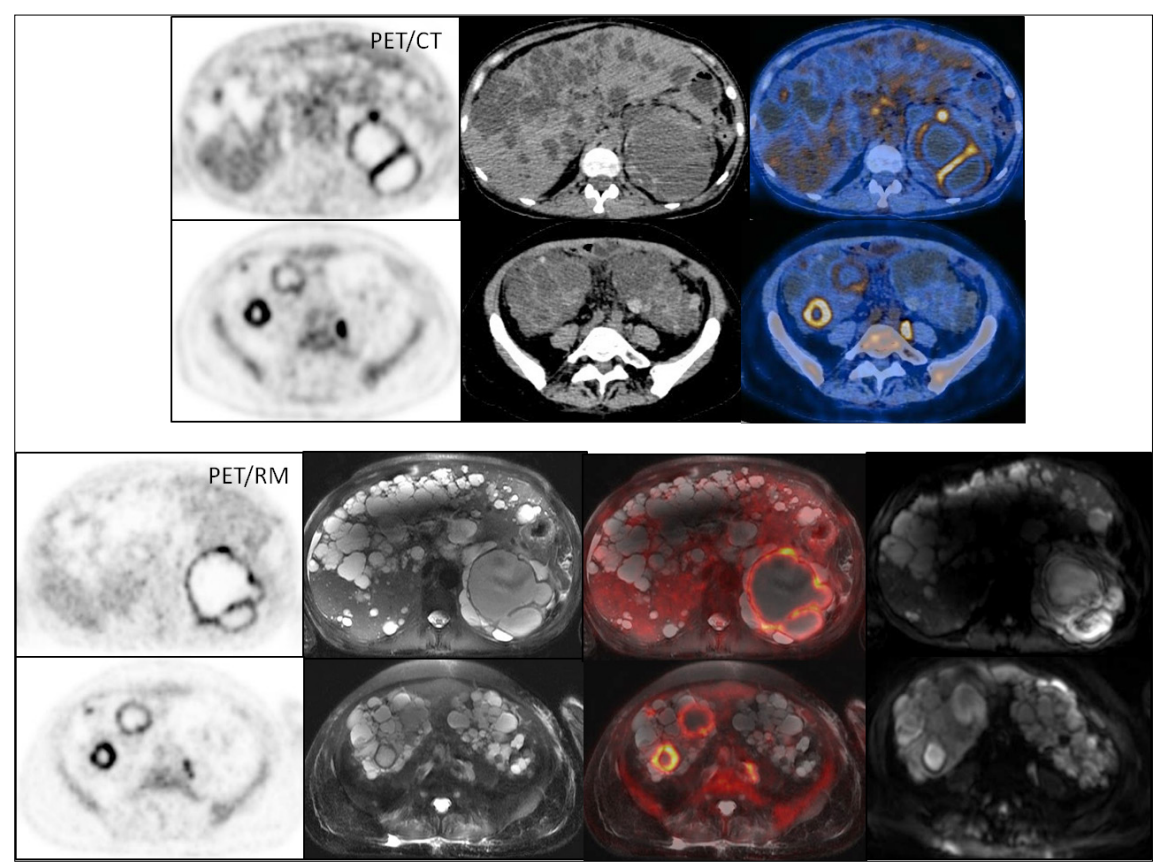

FIGURE 2 PET/CT (top) and PET/MRI (bottom) showing axial slices with T2-weighted sequences and diffusion. A female patient with polycystic kidneys and pain on palpation of the left flank, undergoing investigation due to fever of unknown origin. The PET/CT and PET/MRI studies showed an increase in glycolytic metabolism and diffusion restriction in multiple bilateral renal cysts, suggestive of an active inflammatory/infeccious processes. The case demonstrates the possibility of correlating the molecular information of the PET (glycolytic metabolism of the inflammatory process) with data from functional MRI sequences, namely diffusion (increased cellularity also related to the inflammatory process), increasing the diagnostic conspicuity. 


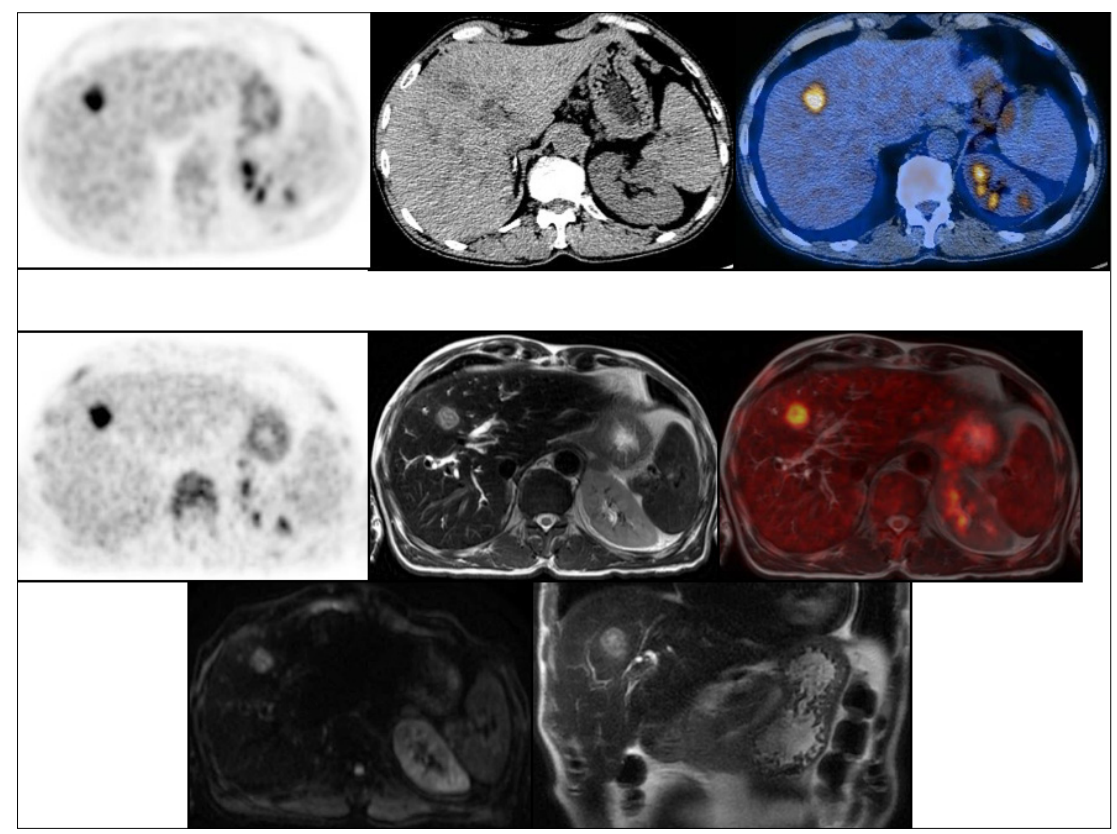

FIGURE 3 PET/CT (top) and PET/MRI (bottom) showing axial slices with T2-weighted sequences and diffusion. Evaluation after chemotherapy for diffuse lymphoma of large B cells. History of right nephrectomy due to lithiasis 4 months before the exam. History of a drain placed in the biliary tract due to choledocholithiasis, repositioned 2 weeks before the exam. A PET/MRI scan allows for a more detailed evaluation of the hepatic lesion seen on a PET/CT and considered suspicious for neoplastic process. On PET/MRI, the hepatic lesion is characterized by thick and irregular walls, with a halo of edema and diffusion restriction, being more probably related to the inflammatory/infectious process. The case demonstrates the superiority of PET/MRI in the evaluation of hepatic lesions.

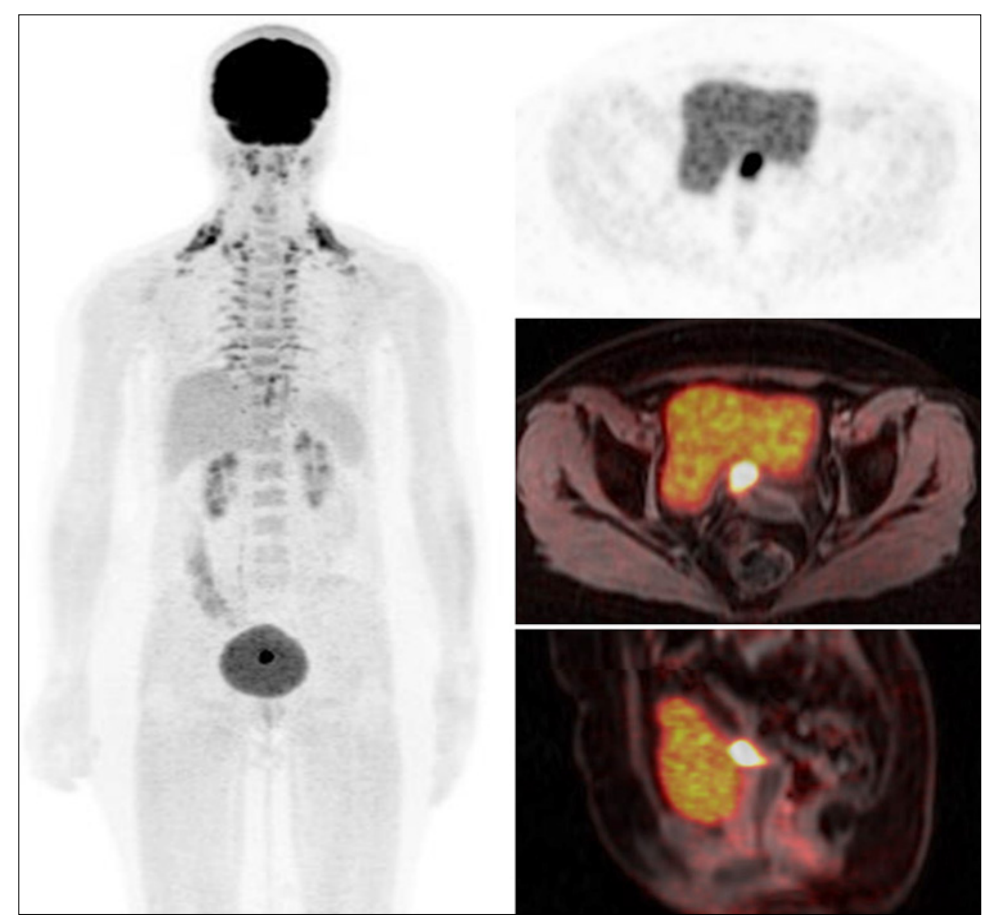

FIGURE 4 Coronal MIP PET and axial slices of T1-weighted PET/MRI sequences. A 46-year-old female patient with a history of cervical cancer treated with surgery and radiation therapy, underwent local recurrence investigation. A PET/MRI scan shows local recurrence in irregular lesions with increased glycolytic metabolism in the retrovesical region, near the vaginal dome. The case shows a potential benefit of using PET/MRI for the evaluation of gynecological neoplasias. 


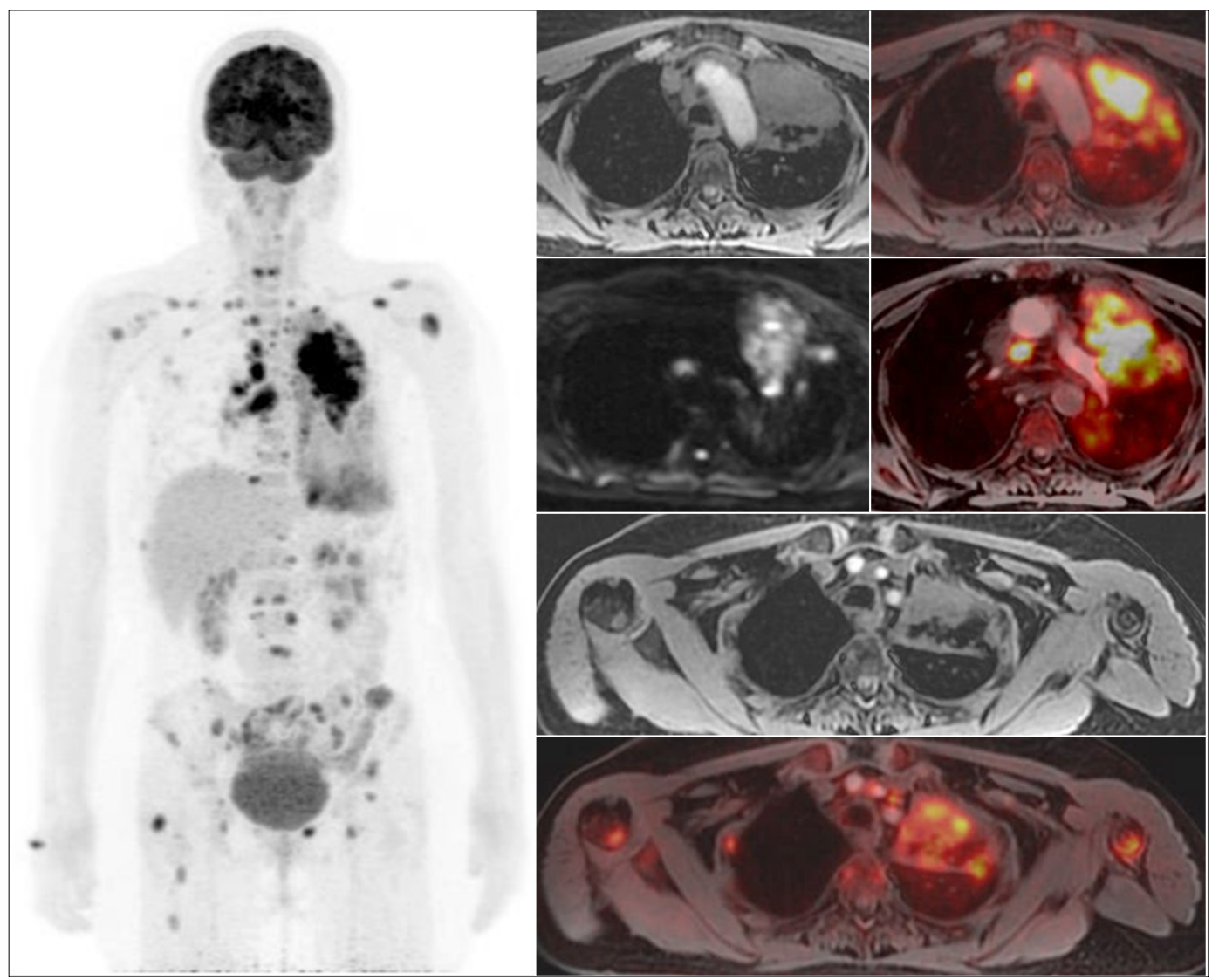

FIGURE 5 Coronal MIP PET and axial slices of T1-weighted PET/MRI sequences and diffusion. Staging of non-small cell lung adenocarcinoma. A PET/MRI scan shows the primary pulmonary mass in the left upper lobe, with signs of thoracic wall infiltration (cortical in the second rib) with bilateral mediastinal lymph node metastases and multiple sparse bone metastases, as well as good morphological correlation in the MR component. This case shows the excellent performance of PET/MRI for staging of lung neoplasia, despite the greater diagnostic capacity of CT in parenchymal evaluations.

\section{Conclusion}

Simultaneous PET/MRI, although widely used as a research tool, could potentially be used in clinical translation as the diagnostic modality of choice in different pathologies.

In oncology, its highest volume niche, the neoplasms that currently require evaluation by PET/CT and MRI can be naturally transferred to PET/MRI. The advantages far exceed the convenience of conducting the examinations at one single time and the lesser exposure to radiation involved, which has been an increasingly worrying issue in the radiological milieu. In this context, children and pregnant women constitute a subgroup of patients who could undoubtedly benefit from this new technology.

One of the most attractive applications of PET/MRI is in neurology. The brain consists of a complex machine which experiences constant changes from a functional standpoint. Thus, the concurrent correlation between anatomy and activity, besides being convenient, is also extremely relevant for the detection of neurological diseases. It has a high impact on neurodegenerative disorders, such as Alzheimer's disease, epilepsy and brain tumors.

PET/MRI once again offers the complementarity between the molecular information from PET and the anatomical-functional information from MRI for evaluating cardiovascular diseases. It permits a detailed evaluation of myocardial perfusion and contributes to the appropriate therapeutic management.

Accordingly, PET/MRI represents the next generation of the molecular hybrid image, offering great possibility of integration into the clinical routine.

\section{Resumo}

Tomografia por emissão de pósitrons/ressonância magnética (PET/RM): atualização e experiência inicial do HC-FMUSP 
A nova tecnologia PET/RM é o protótipo de diagnóstico por imagem híbrido e permite combinar dados moleculares obtidos da tomografia PET e informações morfofuncionais derivadas da ressonância magnética. Avanços recentes relativos a aspectos técnicos desse dispositivo, principalmente após o desenvolvimento de fotomultiplicadores de silício compatíveis com RM, permitiram uma melhora do desempenho diagnóstico da PET/RM traduzida em redução da dose e qualidade superior das imagens. Entre diversas aplicações clínicas, a PET/RM ganha espaço inicialmente no campo da oncologia, onde a RM tem papel essencial na avaliação de tumores primários (limitado no caso da PET/TC), incluindo tumores de próstata, reto e ginecológicos. Por outro lado, a avaliação dos pulmões ainda é um enigma, a despeito de novas sequências de RM que estão sendo criadas para tentar resolver essa questão. Outras indicações clínicas da PET/RM são encontradas no âmbito da neurologia, cardiologia e de processos inflamatórios, nos quais a técnica também abre perspectivas para pacientes pediátricos, já que envolve uma exposição baixíssima à radiação. Nossa revisão teve como objetivo destacar as indicações atuais da PET/RM e discutir os desafios e perspectivas da aplicação dessa técnica no Hospital das Clínicas da FMUSP.

Palavras-chave: Tomografia por Emissão de Pósitrons. Tomografia Computadorizada por Raios X. Espectroscopia de Ressonância Magnética. Diagnóstico por Imagem. Revisão.

\section{References}

1. Townsend DW. Combined positron emission tomography-computed tomography: the historical perspective. S Semin Ultrasound CT MR. 2008; 29(4):232-5.

2. Shao Y, Cherry SR, Farahani K, Slates R, Silverman RW, Meadors K, et al. Development of a PET detector system compatible with MRI/NMR systems. IEEE Trans Nucl Sci. 1997; 44(3):1167-71.

3. Schlemmer HP, Pichler BJ, Schmand M, Burbar Z, Michel C, Ladebeck R, et al. Simultaneous MR/PET imaging of the human brain: feasibility study. Radiology. 2008; 248(3):1028-35.

4. Quick HH. Integrated PET/MR. J Magn Reson Imaging. 2014; 39(2):243-58.

5. Veit-Haibach P, Kuhn FP, Wiesinger F, Delso G, von Schulthess G. PET-MR imaging using a tri-modality PET/CT-MR system with a dedicated shuttle in clinical routine. MAGMA. 2013; 26(1):25-35.

6. Kalemis A, Delattre BM, Heinzer S. Sequential whole-body PET/MR scanner: concept, clinical use, and optimisation after two years in the clinic. The manufacturer's perspective. MAGMA. 2013; 26(1):5-23.

7. Shah SN, Huang SS. Hybrid PET/MR imaging: physics and technical considerations. Abdom Imaging. 2015; 40(6):1358-65.

8. Yoon HS, Ko GB, Kwon SI, Lee CM, Ito M, Chan Song I, et al. Initial results of simultaneous PET/MRI experiments with an MRI-compatible silicon photomultiplier PET scanner. J Nucl Med. 2012; 53(4):608-14.

9. Galiza Barbosa F, Delso G, Ter Voert EE, Huellner MW, Herrmann K, VeitHaibach P. Multi-technique hybrid imaging in PET/CT and PET/MR: what does the future hold? Clin Radiol. 2016; 71(7):660-72.

10. Delso G, Martinez-Möller A, Bundschuh RA, Ladebeck R, Candidus Y, Faul $\mathrm{D}$, et al. Evaluation of the attenuation properties of MR equipment for its use in a whole-body PET/MR scanner. Phys Med Biol. 2010; 55(15):4361-74.
11. Eiber M, Maurer T, Souvatzoglou M, Beer AJ, Ruffani A, Haller B, et al. Evaluation of hybrid 68Ga-PSMA ligand PET/CT in 248 patients with biochemical recurrence after radical prostatectomy. J Nucl Med. 2015; 56(5):668-74.

12. Hofmann M, Pichler B, Schölkopf B, Beyer T. Towards quantitative PET/ MRI: a review of MR-based attenuation correction techniques. Eur J Nucl Med Mol Imaging. 2009; 36(Suppl 1):S93-104

13. Martinez-Möller A, Souvatzoglou M, Delso G, Bundschuh RA, Chefd'hotel $\mathrm{C}$, Ziegler SI, et al. Tissue classification as a potential approach for attenuation correction in whole-body PET/MRI: evaluation with PET/CT data. J Nucl Med. 2009; 50(4):520-6

14. Antoch G, Bockisch A. Combined PET/MRI: a new dimension in wholebody oncology imaging? Eur J Nucl Med Mol Imaging. 2009; 36(Suppl 1):S113-20.

15. Galiza Barbosa F, Delso G, Zeimpekis KG, Ter Voert E, Hüllner M, Stolzmann $\mathrm{P}$, et al. Evaluation and clinical quantification of neoplastic lesions and physiological structures in TOF-PET/MRI and non-TOF/MRI: a pilot study. Q J Nucl Med Mol Imaging. 2015.

16. Drzezga A, Souvatzoglou M, Eiber M, Beer AJ, Fürst S, Martinez-Möller A, et al. First clinical experience with integrated whole-body PET/MR: comparison to PET/CT in patients with oncologic diagnoses. J Nucl Med. 2012; 53(6):845-55

17. Pace L, Nicolai E, Luongo A, Aiello M, Catalano OA, Soricelli A, et al Comparison of whole-body PET/CT and PET/MRI in breast cancer patients: lesion detection and quantitation of 18F-deoxyglucose uptake in lesions and in normal organ tissues. Eur J Radiol. 2014; 83(2):289-96.

18. Hofmann M, Steinke F, Scheel V, Charpiat G, Farquhar J, Aschoff P, et al. MRIbased attenuation correction for PET/MRI: a novel approach combining pattern recognition and atlas registration. J Nucl Med. 2008; 49(11):1875-83.

19. Sekine T, Buck A, Delso G, Ter Voert EE, Huellner M, Veit-Haibach P, et al. Evaluation of atlas-based attenuation correction for integrated PET/MR in human brain: application of a head atlas and comparison to true CT-based attenuation correction. J Nucl Med. 2016; 57(2):215-20.

20. Sekine T, Ter Voert EE, Warnock G, Buck A, Huellner M, Veit-Haibach P, et al. Clinical evaluation of zero-echo-time attenuation correction for brain 18F-FDG PET/MRI: comparison with atlas attenuation correction. J Nucl Med. 2016; 57(12):1927-32.

21. Queiroz MA, Huellner MW. PET/MR in cancers of the head and neck. Semin Nucl Med. 2015; 45(3):248-65.

22. Vandecaveye V, De Keyzer F, Vander Poorten V, Dirix P, Verbeken E, Nuyts $S$, et al. Head and neck squamous cell carcinoma: value of diffusion-weighted MR imaging for nodal staging. Radiology. 2009; 251(1):134-46.

23. Wu LM, Xu JR, Liu MJ, Zhang XF, Hua J, Zheng J, et al. Value of magnetic resonance imaging for nodal staging in patients with head and neck squamous cell carcinoma: a meta-analysis. Acad Radiol. 2012; 19(3):331-40.

24. Becker $M$, Zaidi $H$. Imaging in head and neck squamous cell carcinoma: the potential role of PET/MRI. Br J Radiol. 2014; 87(1036):20130677.

25. Lee SJ, Seo HJ, Cheon GJ, Kim JH, Kim EE, Kang KW, et al. Usefulness of integrated PET/MRI in head and neck cancer: a preliminary study. Nucl Med Mol Imaging. 2014; 48(2):98-105.

26. Leibfarth S, Eckert F, Welz S, Siegel C, Schmidt H, Schwenzer N, et al. Automatic delineation of tumor volumes by co-segmentation of combined PET/MR data. Phys Med Biol. 2015; 60(14):5399-412.

27. Paulus DH, Oehmigen M, Grüneisen J, Umutlu L, Quick HH. Whole-body hybrid imaging concept for the integration of PET/MR into radiation therapy treatment planning. Phys Med Biol. 2016; 61(9):3504-20.

28. Partovi S, Kohan A, Vercher-Conejero JL, Rubbert C, Margevicius S, Schluchter $\mathrm{MD}$, et al. Qualitative and quantitative performance of 18F-FDG-PET/MRI versus 18F-FDG-PET/CT in patients with head and neck cancer. AJNR Am J Neuroradiol. 2014; 35(10):1970-5.

29. Varoquaux A, Rager O, Poncet A, Delattre BM, Ratib O, Becker CD, et al. Detection and quantification of focal uptake in head and neck tumours: (18)F-FDG PET/MR versus PET/CT. Eur J Nucl Med Mol Imaging. 2014; 41(3):462-75

30. Paidpally V, Chirindel A, Chung CH, Richmon J, Koch W, Quon H, et al. FDG volumetric parameters and survival outcomes after definitive chemoradiotherapy in patients with recurrent head and neck squamous cell carcinoma. AJR Am J Roentgenol. 2014; 203(2):W139-45.

31. Pak K, Cheon GJ, Nam HY, Kim SJ, Kang KW, Chung JK, et al. Prognostic value of metabolic tumor volume and total lesion glycolysis in head and neck cancer: a systematic review and meta-analysis. J Nucl Med. 2014; 55(6):884-90. 
32. Picchio M, Kirienko M, Mapelli P, Dell'Oca I, Villa E, Gallivanone F, et al. Predictive value of pre-therapy (18)F-FDG PET/CT for the outcome of (18) F-FDG PET-guided radiotherapy in patients with head and neck cancer. Eur J Nucl Med Mol Imaging. 2014; 41(1):21-31.

33. Fischer B, Lassen U, Mortensen J, Larsen S, Loft A, Bertelsen A, et al. Preoperative staging of lung cancer with combined PET-CT. N Engl J Med. 2009; 361(1):32-9.

34. Stolzmann P, Veit-Haibach P, Chuck N, Rossi C, Frauenfelder T, Alkadhi $\mathrm{H}$, et al. Detection rate, location, and size of pulmonary nodules in trimodality PET/CT-MR: comparison of low-dose CT and Dixon-based MR imaging. Invest Radiol. 2013; 48(5):241-6.

35. Burris NS, Johnson KM, Larson PE, Hope MD, Nagle SK, Behr SC, et al. Detection of small pulmonary nodules with ultrashort echo time sequences in oncology patients by using a PET/MR system. Radiology. 2016; 278(1):239-46.

36. Heusch P, Buchbender C, Köhler J, Nensa F, Gauler T, Gomez B, et al. Thoracic staging in lung cancer: prospective comparison of 18F-FDG PET/MR imaging and 18F-FDG PET/CT. J Nucl Med. 2014; 55(3):373-8.

37. Schwenzer NF, Schraml C, Müller M, Brendle C, Sauter A, Spengler W, et al. Pulmonary lesion assessment: comparison of whole-body hybrid MR/ PET and PET/CT imaging: pilot study. Radiology. 2012; 264(2):551-8.

38. Huellner MW, de Galiza Barbosa F, Husmann L, Pietsch CM, Mader CE, Burger IA, et al. TNM staging of non-small cell lung cancer: comparison of PET/MR and PET/CT. J Nucl Med. 2016; 57(1):21-6.

39. Everitt SJ, Ball DL, Hicks RJ, Callahan J, Plumridge N, Collins M, et al. Differential (18)F-FDG and (18)F-FLT uptake on serial PET/CT imaging before and during definitive chemoradiation for non-small cell lung cancer. J Nucl Med. 2014; 55(7):1069-74.

40. Szyszko TA, Yip C, Szlosarek P, Goh V, Cook GJ. The role of new PET tracers for lung cancer. Lung Cancer. 2016; 94:7-14.

41. Rosenkrantz AB, Friedman K, Chandarana H, Melsaether A, Moy L, Ding YS, et al. Current status of hybrid PET/MRI in oncologic imaging. AJR Am J Roentgenol. 2016; 206(1):162-72

42. Catalano OA, Nicolai E, Rosen BR, Luongo A, Catalano M, Iannace C, et al. Comparison of CE-FDG-PET/CT with CE-FDG-PET/MR in the evaluation of osseous metastases in breast cancer patients. Br J Cancer. 2015; 112(9):1452-60.

43. Melsaether AN, Raad RA, Pujara AC, Ponzo FD, Pysarenko KM, Jhaveri K, et al. Comparison of whole-body (18)F FDG PET/MR imaging and wholebody (18)F FDG PET/CT in terms of lesion detection and radiation dose in patients with breast cancer. Radiology. 2016; 281(1):193-202.

44. Taneja S, Jena A, Goel R, Sarin R, Kaul S. Simultaneous whole-body 18F-FDG PET-MRI in primary staging of breast cancer: a pilot study. Eur J Radiol. 2014; 83(12):2231-9.

45. Botsikas D, Kalovidouri A, Becker M, Copercini M, Djema DA, Bodmer A, et al. Clinical utility of 18F-FDG-PET/MR for preoperative breast cancer staging. Eur Radiol. 2016; 26(7):2297-307.

46. Kong E, Chun KA, Bae YK, Cho IH. Integrated PET/MR mammography for quantitative analysis and correlation to prognostic factors of invasive ductal carcinoma. Q J Nucl Med Mol Imaging. 2016.

47. Minamimoto R, Loening A, Jamali M, Barkhodari A, Mosci C, Jackson T, et al. Prospective comparison of $99 \mathrm{mTc}$-MDP scintigraphy, combined $18 \mathrm{~F}-\mathrm{NaF}$ and 18F-FDG PET/CT, and whole-body MRI in patients with breast and prostate cancer. J Nucl Med. 2015; 56(12):1862-8

48. van Kruchten M, Vries EG, Brown M, Vries EF, Glaudemans AW, Dierckx RA, et al. PET imaging of oestrogen receptors in patients with breast cancer. Lancet Oncol. 2013; 14(11):e465-75.

49. van Kruchten M, Glaudemans AW, de Vries EF, Beets-Tan RG, Schröder CP, Dierckx RA, et al. PET imaging of estrogen receptors as a diagnostic tool for breast cancer patients presenting with a clinical dilemma. J Nucl Med. 2012; 53(2):182-90.

50. Sun Y, Yang Z, Zhang Y, Xue J, Wang M, Shi W, et al. The preliminarystudy of $16 \alpha-[18 \mathrm{~F}]$ fluoroestradiol PET/CT in assisting the individualized treatment decisions of breast cancer patients. PLoS One. 2015; 10(1):e0116341.

51. Yang Z, Sun Y, Zhang Y, Xue J, Wang M, Shi W, et al. Can fluorine-18 fluoroestradiol positron emission tomography-computed tomography demonstrate the heterogeneity of breast cancer in vivo? Clin Breast Cancer. 2013; 13(5):359-63.

52. Reiner CS, Stolzmann P, Husmann L, Burger IA, Hüllner MW, Schaefer NG, et al. Protocol requirements and diagnostic value of PET/MR imaging for liver metastasis detection. Eur J Nucl Med Mol Imaging. 2014; 41(4):649-58.

53. Lee DH, Lee JM, Hur BY, Joo I, Yi NJ, Suh KS, et al. Colorectal cancer liver metastases: diagnostic performance and prognostic value of PET/MR imaging. Radiology. 2016; 280(3):782-92.
54. Hope TA, Pampaloni MH, Nakakura E, VanBrocklin H, Slater J, Jivan S, et al. Simultaneous (68)Ga-DOTA-TOC PET/MRI with gadoxetate disodium in patients with neuroendocrine tumor. Abdom Imaging. 2015; 40(6):1432-40.

55. Ghaneh P, Wong WL, Titman A, Plumpton C, Vinjamuri S, Johnson C. PETPANC: multi-centre prospective diagnostic accuracy and clinical value trial of FDG PET/CT in the diagnosis and management of suspected pancreatic cancer. J Clin Oncol. 2016; 34(Suppl):Abstract 4008.

56. Chen BB, Tien YW, Chang MC, Cheng MF, Chang YT, Wu CH, et al. PET/ $\mathrm{MRI}$ in pancreatic and periampullary cancer: correlating diffusion-weighted imaging, MR spectroscopy and glucose metabolic activity with clinical stage and prognosis. Eur J Nucl Med Mol Imaging. 2016; 43(10):1753-64.

57. Gaertner FC, Beer AJ, Souvatzoglou M, Eiber M, Fürst S, Ziegler SI, et al Evaluation of feasibility and image quality of 68Ga-DOTATOC positron emission tomography/magnetic resonance in comparison with positron emission tomography/computed tomography in patients with neuroendocrine tumors. Invest Radiol. 2013; 48(5):263-72.

58. Mayerhoefer ME, Ba-Ssalamah A, Weber M, Mitterhauser M, Eidherr H, Wadsak W, et al. Gadoxetate-enhanced versus diffusion-weighted MRI for fused Ga-68-DOTANOC PET/MRI in patients with neuroendocrine tumours of the upper abdomen. Eur Radiol. 2013; 23(7):1978-85

59. Park H, Wood D, Hussain H, Meyer CR, Shah RB, Johnson TD, et al. Introducing parametric fusion PET/MRI of primary prostate cancer. J Nucl Med. 2012; 53(4):546-51.

60. Vargas HA, Grimm J, F Donati O, Sala E, Hricak H. Molecular imaging of prostate cancer: translating molecular biology approaches into the clinical realm. Eur Radiol. 2015; 25(5):1294-302

61. Souvatzoglou M, Eiber M, Takei T, Fürst S, Maurer T, Gaertner F, et al Comparison of integrated whole-body [11C]choline PET/MR with PET/CT in patients with prostate cancer. Eur J Nucl Med Mol Imaging. 2013; 40(10):1486-99.

62. Wetter A, Lipponer C, Nensa F, Beiderwellen K, Olbricht T, Rübben H, et al Simultaneous $18 \mathrm{~F}$ choline positron emission tomography/magnetic resonance imaging of the prostate: initial results. Invest Radiol. 2013; 48(5):256-62.

63. Rietbergen DD, van der Hiel B, Vogel W, Stokkel MP. Mediastinal lymph node uptake in patients with prostate carcinoma on F18-choline PET/CT Nucl Med Commun. 2011; 32(12):1143-7.

64. Afshar-Oromieh A, Haberkorn U, Schlemmer HP, Fenchel M, Eder M, Eisenhut M, et al. Comparison of PET/CT and PET/MRI hybrid systems using a 68Ga-labelled PSMA ligand for the diagnosis of recurrent prostate cancer: initial experience. Eur J Nucl Med Mol Imaging. 2014; 41(5):887-97.

65. Afshar-Oromieh A, Zechmann CM, Malcher A, Eder M, Eisenhut M, Linhar HG, et al. Comparison of PET imaging with a (68)Ga-labelled PSMA ligand and (18)F-choline-based PET/CT for the diagnosis of recurrent prostate cancer. Eur J Nucl Med Mol Imaging. 2014; 41(1):11-20.

66. Eiber M, Martinez-Möller A, Souvatzoglou M, Holzapfel K, Pickhard A, Löffelbein D, et al. Value of a Dixon-based MR/PET attenuation correction sequence for the localization and evaluation of PET-positive lesions. Eur J Nucl Med Mol Imaging. 2011; 38(9):1691-701.

67. Donati OF, Lakhman Y, Sala E, Burger IA, Vargas HA, Goldman DA, et al Role of preoperative MR imaging in the evaluation of patients with persistent or recurrent gynaecological malignancies before pelvic exenteration. Eur Radiol. 2013; 23(10):2906-15

68. Sala E, Rockall AG, Freeman SJ, Mitchell DG, Reinhold C. The added role of MR imaging in treatment stratification of patients with gynecologic malignancies: what the radiologist needs to know. Radiology. 2013; 266(3):717-40

69. Queiroz MA, Kubik-Huch RA, Hauser N, Freiwald-Chilla B, von Schulthess G, Froehlich JM, et al. PET/MRI and PET/CT in advanced gynaecological tumours: initial experience and comparison. Eur Radiol. 2015; 25(8):2222-30.

70. Kanda T, Kitajima K, Suenaga Y, Konishi J, Sasaki R, Morimoto K, et al Value of retrospective image fusion of 18F-FDG PET and MRI for preoperative staging of head and neck cancer: comparison with PET/CT and contrastenhanced neck MRI. Eur J Radiol. 2013; 82(11):2005-10.

71. Kitajima K, Suenaga Y, Ueno Y, Kanda T, Maeda T, Takahashi S, et al. Value of fusion of PET and MRI for staging of endometrial cancer: comparison with 18F-FDG contrast-enhanced PET/CT and dynamic contrast-enhanced pelvic MRI. Eur J Radiol. 2013; 82(10):1672-6.

72. Grueneisen J, Schaarschmidt BM, Beiderwellen K, Schulze-Hagen A, Heubner M, Kinner S, et al. Diagnostic value of diffusion-weighted imaging in simultaneous 18F-FDG PET/MR imaging for whole-body staging of women with pelvic malignancies. J Nucl Med. 2014; 55(12):1930-5. 
73. Lee SI, Catalano OA, Dehdashti F. Evaluation of gynecologic cancer with MR imaging, 18F-FDG PET/CT, and PET/MR imaging. J Nucl Med. 2015; 56(3):436-43.

74. Cheson BD, Fisher RI, Barrington SF, Cavalli F, Schwartz LH, Zucca E, et al.; Alliance, Australasian Leukaemia and Lymphoma Group; Eastern Cooperative Oncology Group; European Mantle Cell Lymphoma Consortium; Italian Lymphoma Foundation; European Organisation for Research; Treatment of Cancer/Dutch Hemato-Oncology Group; Grupo Español de Médula Ósea; German High-Grade Lymphoma Study Group; German Hodgkin's Study Group; Japanese Lymphorra Study Group; Lymphoma Study Association; NCIC Clinical Trials Group; Nordic Lymphoma Study Group; Southwest Oncology Group; United Kingdom National Cancer Research Institute. Recommendations for initial evaluation, staging, and response assessment of Hodgkin and non-Hodgkin lymphoma: the Lugano classification. J Clin Oncol. 2014; 32(27):3059-68.

75. Heacock L, Weissbrot J, Raad R, Campbell N, Friedman KP, Ponzo F, et al. PET/MRI for the evaluation of patients with lymphoma: initial observations. AJR Am J Roentgenol. 2015; 204(4):842-8.

76. Platzek I, Beuthien-Baumann B, Langner J, Popp M, Schramm G, Ordemann $\mathrm{R}$, et al. PET/MR for therapy response evaluation in malignant lymphoma: initial experience. MAGMA. 2013; 26(1):49-55.

77. Platzek I, Beuthien-Baumann B, Ordemann R, Maus J, Schramm G, Kitzler $\mathrm{HH}$, et al. FDG PET/MR for the assessment of lymph node involvement in lymphoma: initial results and role of diffusion-weighted MR. Acad Radiol. 2014; 21(10):1314-9.

78. Giraudo C, Raderer M, Karanikas G, Weber M, Kiesewetter B, Dolak W, et al. 18F-fluorodeoxyglucose positron emission tomography/magnetic resonance in lymphoma: comparison with 18F-fluorodeoxyglucose positron emission tomography/computed tomography and with the addition of magnetic resonance diffusion-weighted imaging. Invest Radiol. 2016; 51(3):163-9.

79. Herrmann K, Queiroz M, Huellner MW, Galiza Barbosa F, Buck A, Schaefer $\mathrm{N}$, et al. Diagnostic performance of FDG-PET/MRI and WB-DW-MRI in the evaluation of lymphoma: a prospective comparison to standard FDGPET/CT. BMC Cancer. 2015; 15:1002.

80. Drzezga A, Barthel H, Minoshima S, Sabri O. Potential clinical applications of PET/MR imaging in neurodegenerative diseases. J Nucl Med. 2014; 55(Suppl 2):47S-55S.
81. Fink JR, Muzi M, Peck M, Krohn KA. Multimodality brain tumor imaging: MR imaging, PET, and PET/MR imaging. J Nucl Med. 2015; 56(10):1554-61.

82. Heiss WD. The potential of PET/MR for brain imaging. Eur J Nucl Med Mol Imaging. 2009; 36(suppl 1):S105-12

83. Barthel H, Schroeter ML, Hoffmann KT, Sabri O. PET/MR in dementia and other neurodegenerative diseases. Semin Nucl Med. 2015; 45(3):224-33.

84. Ratib O, Nkoulou R. Potential applications of PET/MR imaging in Cardiology. J Nucl Med. 2014; 55(Suppl. 2):40S-6S

85. Rischpler C, Nekolla SG, Dregely I, Schwaiger M. Hybrid PET/MR imaging of the heart: potential, initial experiences, and future prospects. J Nucl Med. 2013; 54(3):402-15

86. Di Gialleonardo V, Wilson DM, Keshari KR. The potential of metabolic imaging. Semin Nucl Med. 2016; 46(1):28-39.

87. Nawaz A, Torigian DA, Siegelman ES, Basu S, Chryssikos T, Alavi A. Diagnostic performance of FDG-PET, MRI, and plain film radiography (PFR) for the diagnosis of osteomyelitis in the diabetic foot. Mol Imaging Biol. 2010; 12(3):335-42.

88. Rosado-de-Castro PH, Lopes de Souza SA, Alexandre D, Barbosa da Fonseca LM, Gutfilen B. Rheumatoid arthritis: nuclear medicine state-of-the-art imaging. World J Orthop. 2014; 5(3):312-8.

89. Catalano OA, Gee MS, Nicolai E, Selvaggi F, Pellino G, Cuocolo A, et al Evaluation of quantitative PET/MR enterography biomarkers for discrimination of inflammatory strictures from fibrotic strictures in Crohn disease. Radiology. 2016; 278(3):792-800.

90. Wiehr S, Warnke P, Rolle AM, Schütz M, Oberhettinger P, Kohlhofer U, et al. New pathogen-specific immunoPET/MR tracer for molecular imaging of a systemic bacterial infection. Oncotarget. 2016; 7(10):10990-1001.

91. Hirsch FW, Sattler B, Sorge I, Kurch L, Viehweger A, Ritter L, et al. PET/MR in children. Initial clinical experience in paediatric oncology using an integrated PET/MR scanner. Pediatr Radiol. 2013; 43(7):860-75.

92. Purz S, Sabri O, Viehweger A, Barthel H, Kluge R, Sorge I, et al. Potential pediatric applications of PET/MR. J Nucl Med. 2014; 55(Suppl. 2):32S-9S

93. Schäfer JF, Gatidis S, Schmidt H, Gückel B, Bezrukov I, Pfannenberg CA, et al. Simultaneous whole-body PET/MR imaging in comparison to PET/CT in pediatric oncology: initial results. Radiology. 2014; 273(1):220-31. 